\title{
Evolutionary Concept Analysis on HumorTherapy: A Virtual Study
}

\section{Raziyeh Ghafouri*}

Department of Nursing, Student Committee of Research, Nursing and Midwifery faculty, Iran University of Medical Science, Tehran, Iran

Study Area:Tehran, Iran

Coordinates: $35^{\circ} 41^{\prime} 46^{\prime \prime} \mathrm{N}_{51^{\circ}} 25^{\prime} 23^{\prime \prime} \mathrm{E}$

Key words: Laughter, Dignify care, Evolutionary Concept Analysis.

\section{Abstract}

Humor therapy is the use of the power of smiles and laughter to aid healing. The present study aims to clarify and reduce the semantic ambiguities of the concept of humor therapy and also increase the understanding of its features, outcomes, and applications. A keyword search on literature was conducted to explore the concept of humor therapy. Rodgers' evolutionary concept analysis was used in the present study. Finally, the data were analyzed using content analysis. Humor therapy is an interactive process and uses the positive effects of laughter in the treatment of patients. Personality and cultural factors and psychological status of individuals affect the application of this therapy. The most important antecedents of humor therapy, for having a positive impact include mutual respect, not offending others, and observance of the dignity of others, especially minorities and the poor. In addition, health promotion in the two dimensions of personal (physical and mental) and interpersonal is the major outcome of humor therapy.

analysis of the concept of humor therapy and identification of its features, antecedents, and outcomes aiming at the proposal of a comprehensive definition of humor therapy.

Over the past few decades, various methods of concept analysis have been developed and applied, one of which is Rodgers' method. Rodgers proposed his conceptual clarif ication method based on the evolutionary approach. This method is suitable for analyzing the concepts which have been applied without a clear understanding of their features (Rodgers, 200o) and are dependent on the cultural and underlying contexts. The present study, using Rodgers' evolutionary concept analysis, aims to clarify and reduce the semantic ambiguities of the concept of humor therapy and also increase the understanding of its features, outcomes, and applications.

\section{Methodology:}

WConsidering the dependence of laughter and humor on the cultural and underlying contexts, the present study was conducted based on Rodgers' evolutionary concept analysis (Rodgers, 200o). This method includes the determination of the desired concept, determination and selection of the appropriate scope of data collection, collection and analysis of data in order to achieve the features of the concept and its antecedents and outcomes, and identification of the relevant and alternatives conduction of many studies about the positive impact humor therapy, few studies have been conducted on the

*Author:ghafouri.r@tak.iums.ac.ir 
concepts for further clarif ication of the concept.

A keyword search of electronic databases including PUBMED, Ovid, ScienceDirect, and ProQuest and 176 articles was performed. The keywords, "humor therapy" and "humor" were searched and extracted. After removing the duplicates, the quality of the resulting articles was examined based on an inclusion criterion. The criteria involved Farsi or English studies about the therapeutic effects of laughter and humor on the human body. In the next step, the quality of articles was measured using Strobe and 33 articles were selected. Figure 1 shows the process of the literature review and selection of articles.

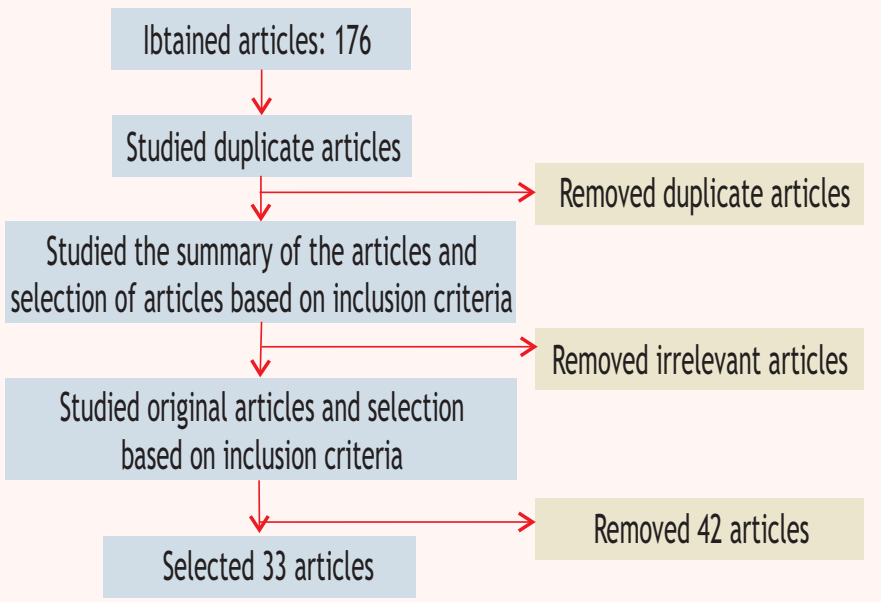

Figure-1: The process of the literature review and selection of the articles

Since Rodgers (2000) method is based on the inductive approach, the thematic analysis method was used in this study for data analysis. Units of analysis were the extracted articles and their semantic units were extracted with a code given to each of them. Then, these codes were classified for the identification of features, antecedents, and outcomes of the desired concept.

\section{Results:}

Perceived definition and features of Humor Therapy: humor therapy is an interactive process which uses the positive effects of laughter in treatment. In addition, health promotion in the two dimensions of personal (physical and mental) and interpersonal is the outcome of humor therapy.

Antecedents: mutual respect, not offending others, and observance of the dignity of other, especially minorities and the poor were found to be the most important antecedents of humor therapy. Personality and cultural factors and psychological status of individuals also affect the application of humor therapy. Greengross \& Miller (2011), Zhao et al., (2014) and Martin (2003) forwarded the articles related to antecedents viz., Mutual respect, Not offending others and observing their dignity and Personality and cultural factors and psychological status of humor therapy.

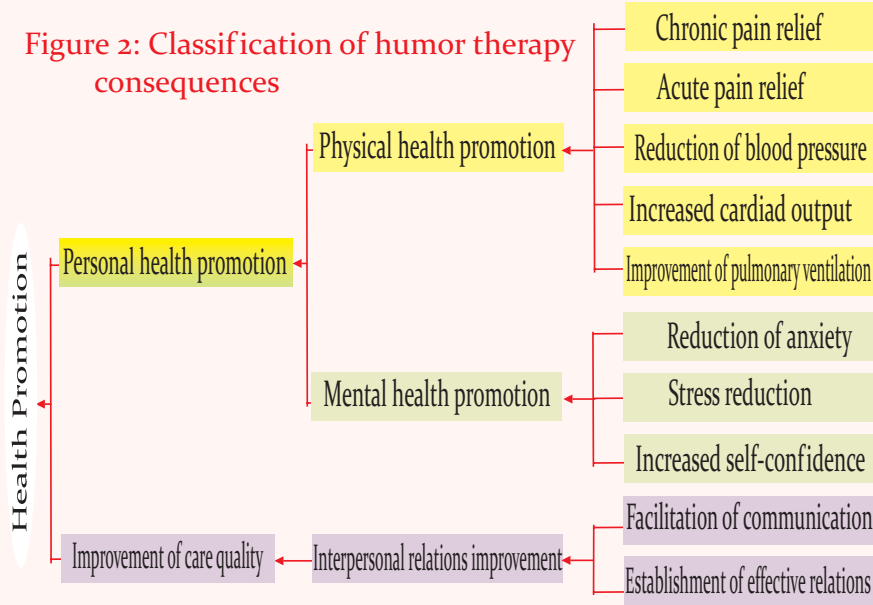

Consequences: the main outcome of humor therapy is health promotion in personal and interpersonal dimensions. Figure 2 shows a classification of humor therapy consequences.

Table 2: Articles related to consequences of humor therapy

\begin{tabular}{ll}
\hline Outcomes & Articles \\
\hline Acute pains relief. & (Weisenberg et al., 1995; Mora-Ripoll, 2011,
\end{tabular}
Matz \& Brown, 1998).

Chronic pains relief. (Adams, 2002; Weisenberg et al., 1995; Mora-Ripoll, 2011).

Increased cardiac (Sugawara et al., 2010; Miller et al., 2006; output. Mora-Ripoll, 2011; Lebowitz et al., 2011; Buchowski et al., 2007; Ganz \& Jacobs, 2014).

Reduction of blood pressure.

Strengthening the immune system.

(Miller et al., 2006; Mora-Ripoll, 2011; Miller \& Fry, 2009).

(Bennett et al., 2003; Mora-Ripoll, 2011; Lebowitz et al., 2011; Ganz \& Jacobs, 2014; Hayashi \& Murakami, 2009).

Improvement of pulmonary ventilation.

(Hostetler, 2002; Miller et al., 2006; MoraRipoll, 2011; Lebowitz et al., 2011; Ganz \& Jacobs, 2014; Buchowski et al., 2007).

Increased self-confi- (Bennett et al., 2003, Mora-Ripoll, 2011, dence.

Ganz \& Jacobs, 2014, José et al., 2007, Bennett \& Lengacher, 2006).

Reduction of blood sugarand its adverse (Hayashi et al., 2007). effects in diabetics. Reduction of stress.

(Bennett et al., 2003; Mora-Ripoll, 2011; Ganz \& Jacobs, 2014; José et al., 2007; Watson et al.,2007; James, 1995).

Reduction of anxiety.

(Bennett et al., 2003; Mora-Ripoll, 2011; Bennett \& Lengacher, 2006; Ganz \& Jacobs, 2014; Joséet al., 2007; James, 1995).

Facilitation of communications.

(Riley, 2004; Watson et al., 2007; MoraRipoll, 2011; Matz \& Brown, 1998).

Establishment of effective relations.
(Riley, 2004; Watson et al., 2007; MoraRipoll, 2011; Matz \& Brown, 1998). 




Discussion:

The process of humor therapy emphasizes the observance of mutual respect and dignity of other. Cultural beliefs and personality parameters also influence this process. Violation of mutual respect in humor therapy leads to the establishment of ineffective relations or breakup. McCreaddie \& Payne (2010) also argue that laughter causes the continuation of effective relations. However, they assert that laughter should aim at encouraging individuals to maintain effective communications, rather than bothering others.

Ghaffari et al. (2015) state that laughter is a social, emotional, behavioral, and cognitive phenomenon which facilitates the establishment, continuation, and improvement of relations. McCreaddie \& Wiggins (2009) argue that laughter is a complex phenomenon that is associated with situational, social, physiological, behavioral, emotional, and cognitive aspects and emphasize that it is important who uses laughter when, where, and how. Greengross \& Miller (2011) also emphasize that people use laughter in accordance to their culture. Kuiper et al. (1992) state that laughter has positive impacts on human life. Schermer et al. (2013) argue that personality factors and phenotype influence the use of laughter. Marin (2003) believes that laughter facilitates relations and reduces conflicts in relationships.

Mora-Ripoll (2010) state that laughter has many positive effects and can be used as a complementary treatment. In another paper, he also asserts that laughter has many positive impacts on mental, psychological, social, and physical aspects of life and can be helpful in the treatment of patients because of its few side effects. In addition, he also believes that laughter can reduce tension, fatigue, and frustration of medical workers (Mora-Ripoll, 2011). According to the World Health Organization, Chang states that humor therapy programs are expanding around the world and there is a growing willingness among patients for the use of laughter in medical relations (Chang et al., 2013). Based on the results of the present study and other studies, application of laughter, in a non-damaging manner with the observance of mutual respect and dignity, is associated with various advantages such as the promotion of physical and mental health.

Acknowledgements:

The authors would like to thank all participants for their kind collaboration.

\section{References:}

Adams, P. (2002): Humour and love: the origination of clown therapy. Postgrad. Med.J.. 78:447-448.

Bennett, H.J. (2003): Humor in medicine. South. Med. J.,96(12): 1257-1261.

Bennett, M.P. \& Lengacher, C. (2006): Humor and laughter may influence health: II. Complementary therapies and humor in a clinical population. Evid Based Complement Alternat Med., 3(2):187-19o.

Bennett, M.P., Zeller, J.M., Rosenberg, L. \& McCann, J. (2003):The effect of mirthful laughter on stress and natural killer cell activity. Altern. Ther. Health. Med., 9(2):38-45.

Brutsche, M.H., Grossman, P., Müller, R.E., Wiegand, J., Pello, B. F. \& Ruch, W. (2008): Impact of laughter on air trapping in severe chronic obstructive lung disease. Int. I. Chron. Obstruct.Pulmon.Dis., 3(1):185-192.

Buchowski, M.S., Majchrzak, K.M., Blomquist, K., Chen, K.Y., Byrne, D.W., \& Bachorowski, J.A. (2007): Energy expenditure of genuine laughter. Int. J. Obes. (Lond)., 31(1):131-137.

Chang, C., Tsai, G. \& Hsieh, C-J. (2013): Psychological, immunological and physiological effects of a Laughing Qigong Program (LQP) on adolescents. Complement. Ther. Med., 21(6):66o-668.

Cutdiffe, J.R. \& McKenna, H.P. (2005): The Essential Concept of Nursing, Philadelphia, Pub. by: Elsevier Saunders Co.

Edwards, J.R., \& Cooper, C.L (1988): The impacts of positive psychological states on physical health: A review and theoretical framework. Soc. Sci. Med., 27(12):1447-1459.

Ganz, F.D., Jacobs, J.M. (2014): The effect of humor on elder mental and physical health. Geriatr Nurs., 35(3):205-2511.

Ghaffare, F., Dehghan-Nayeri, N. \& Sgali, M. (2015): Nurses' experiences of humour in clinical settings. Med. J. Islam. Repub. Iran, 29:182.

Greengross, G. \& Miller, G. (2011): Humor ability reveals intelligence, predicts mating success, and is higher in males. Intelligence, 39:188-192.

Hayashi, T. \& Murakami, K. (2009): The effects of laughter on post-prandial glucose levels and gene expression in type 2 diabetic patients. LifeSci., 85(5-6):185-187.

Hayashi, T., Urayama, O., Hori. M., Sakamoto. S., Nasir, U.M., Iwanaga, S., Hayashi, K., Suzuki, F., Kawai, K. \& Murakami, K. (2007): Laughter modulates prorenin receptor gene expression in patients with type 2 diabetes. I. Psychosom. Res. 62(6):703-706.

Hostetler, J. (2002): Humor, spirituality and well-being. Persp. Sci. Christ. Faith, 52:108-113.

Jalali, S.F., Kheirkhah, F., Ahmadi, M.H. \& Zarei, B.S., (2008): Effect of laughter therapy on blood pressure patients with essential hypertention. J. Babol Uni. Med. Sci., 10:35-40.

James, D.H. (1995): Humor: Aholistic nursing intervention. I. Holist. Nurs., 13(3),:239-247 
Jose, H., P Parreira, P., Thorson, J.A. \& Allwardt, D. (2007): A factor-analytic study of the multidimensional sense of humor scale with a Portuguese sample. N. Am. J. Psychol., 9(3):595-610.

Kuiper, N. A., Martin, R. A., \& Dance, K. A. (1992): Sense of humor and enhanced quality of life. Pers. Indiv. Differ., 13:1273-1283.

Lebowitz, K.R., Suh, S., Diaz, P.T. \& Emery, C.F. (2011): Effects of humor and laughter on psychological functioning, quality of life, health status, and pulmonary functioning among patients with chronic obstructive pulmonary disease: a preliminary investigation. Heart Lung, 40(4):310-319.

Martin, R.A. (2003): Sense of humor. In Lopez, S.J. \& Snyder, C.R. (eds.) Positive psychological assessment: A handbook of models and measures, 313-326. Washington, DC., Pub. by: American Psychological Association.

Matz, A. \& Brown, S.T. (1998): Humour and pain management. L. Holist. Nurs., 16:68-75.

McCreaddie, M. \& Payne, S. (2010): Evolving grounded theory methodology: towards a discursive approach. Int. J. Nurs. Stud., 47(6): 781-793.

McCreaddie, M, \& Wiggins, S. (2009): Reconciling the good patient persona with problematic and non-problematic humour: a grounded theory. Int. I. Nurs. Stud., 46(8):10791091.

Miller, M. \& Fry, W.F. (2009): The effect of mirthful laughter on the human cardiovascular system. Med. Hypo., 73:636-639.

Miller, M., Mangano, C., Park, Y., Goel, R., Plotnick, G.D. \& Vogel, R.A. (2006): Impact of cinematic viewing on endothelial function. Heart, 92(2):261-262.
Mora-Ripoll, R. (2010): The therapeutic value of laughter in medicine. Altern. Ther. Health Med., 16(6):56-64.

Mora-Ripoll, R. (2011): Potential health benefits of simulated laughter: a narrative review of the literature and recommendations for future research. Complement Ther. Med.,19(3):170-177.

Riley, J.K. (2004): Communication in Nursing. $5^{\text {th }}$ edition, ed. Philadelphia: Mosby Co.

Rodgers, B.L. (200o): Philosophical foundations of concept development. Concept Development in Nursing: Foundations, Techniques and Applications (Rodgers, Concept Development in Nursing), 7-37, Pub. by: Elsevier Health.

Schermer, J., Martin, R. A., Martin, N. G., Lynskey, M., \& Vernon, P. A. (2013). The general factor ofpersonality and humor styles. Pers. Indiv. Differ., 54:890-893.

Sugawara, J., Tarumi, T. \& Tanaka, H. (2010): Effect of mirthful laughter on vascular function. Am.J. Cardiol.,106(6):856-859.

Watson, K.K., Matthews, B.J., \& Allman, J.M. (2007): Brain activation during sight gags and language-dependent humor. Cerebral Cortex, 17(2):314-324.

Weisenberg, M., Tepper, I. \& Schwarzwald, J. (1995): Humor as a cognitive technique for increasing pain tolerance. $\underline{\text { Pain, }}$ 63(2):207-212.

Zhao, J., Wang, Y. \& Kong, F. (2014): Exploring the mediation effect of social support and self-esteem on the relationship between humor style and life satisfaction in Chinese college students. Pers. Indiv. Differ., 64:126-130. 